\title{
Persistent Buccal Swelling: Diagnostic Dilemma
}

\author{
Malarkodi Thanthoni ${ }^{1}$, Sathasivasubramanian S ${ }^{2}$, Aravind Warrier S ${ }^{1}$ \\ 1. Oral Medicine and Radiology, Faculty of Dental Sciences, Sri Ramachandra University, Chennai, IND 2. Oral \\ Medicine \& Radiology, Faculty of Dental Sciences, Sri Ramachandra University, Chennai, IND
}

Corresponding author: Malarkodi Thanthoni, tmalarkodi@gmail.com

\section{Abstract}

Taking a systematic and comprehensive patient history is undoubtedly an essential tool for a proper diagnosis. We report a unique case of a patient presenting with persistent buccal swelling, a rare presentation of two unrelated pathologies occurring concurrently. In this case, the presence of a lipoma was concealed by a dental abscess and an incomplete patient history.

Categories: Pathology, Miscellaneous, Other

Keywords: lipoma, dental abscess, buccal swelling

\section{Introduction}

Lipomas are benign tumors composed of a well-circumscribed mass of mature adipose tissue [1]. Although it is one of the more common mesenchymal neoplasms to occur elsewhere in the body (such as the trunk, shoulder axilla, etc.), a lipoma is relatively uncommon in the submandibular region [2]. Lipomas occurring in the head region account for $15 \%$ to $20 \%$ of cases [3], and the peak incidence is during a patient's fifth or sixth decade of life [4]. Lipomas usually present as asymptomatic, slow-growing masses, and the clinical course can last for several years [5]. We report an uncommon presentation of a lipoma occurring in the submandibular region in a 53-year-old South Indian man.

\section{Case Presentation}

A 53-year-old man sought treatment at the department of oral medicine and radiology at Sri Ramachandra University in Chennai, India, for a painful and progressive swelling involving the right mandibular region for four days. It was associated with a toothache on the right lower jaw. The pain in the tooth was dull, continuous, and aggravated on taking hot or cold beverages. The swelling was small when he initially noticed it and gradually increased to the presenting size. The patient had visited a private dentist a day before, where an orthopantomogram was taken, and he was advised to undergo extraction after a course of antibiotics and non-steroidal anti-inflammatory drugs. His medical history was noncontributory. Extra orally, a single, well-defined swelling was evident in the right lower jaw region, with signs of inflammation. The swelling was $4 \mathrm{~cm} \times 5 \mathrm{~cm}$, warm, tender, soft, compressible, and not fluctuant. Intraoral examination

Received 11/28/2018 Review began 11/30/2018 Review ended 12/09/2018 Published 12/11/2018

\section{(c) Copyright 2018}

Thanthoni et al. This is an open access article distributed under the terms of the Creative Commons Attribution License CC-BY 3.0., which permits unrestricted use, distribution, and reproduction in any medium, provided the original author and source are credited. revealed dental caries in 47 , with gross destruction of the crown and mucobuccal fold obliteration in relation to 47 . A provisional diagnosis of dental caries in 47 , with a dentoalveolar abscess, was promptly made. The previous orthopantomogram revealed radiolucency in 47 with gross destruction of the crown associated with radiolucency around the roots (Figure 1). No other associated pathologies were evident. The patient was advised to continue the same medication for four more days. Four days later, the patient reported with painless swelling, which had reduced in size to $3 \mathrm{~cm} \times 4 \mathrm{~cm}$ involving the same site. The swelling was nontender, soft, and compressible; it was not fluctuant, pulsatile, or fixed to the skin and underlying bone. The results of the transillumination screening were negative.

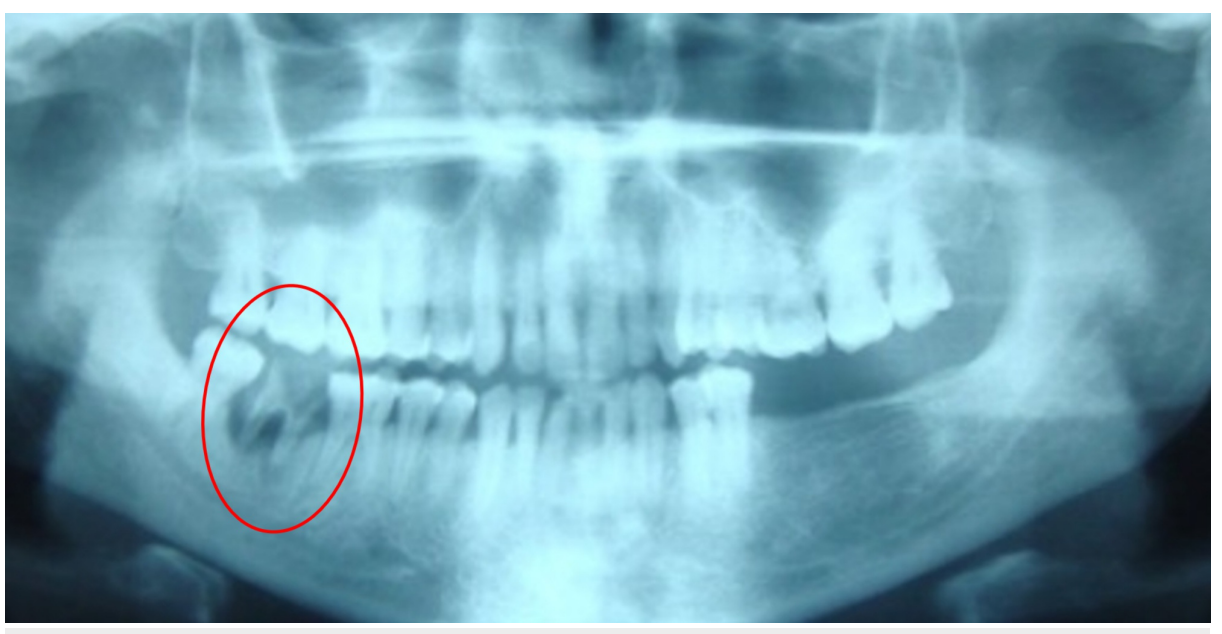




\section{Cureus}

\section{FIGURE 1: Orthopantomogram shows radiolucency in tooth 47 with gross destruction of the crown associated with radiolucency around the roots}

Given that the patient was asymptomatic, we extracted tooth 47 while he was under local anesthesia. The postoperative period was uneventful. When the patient was evaluated one week later, the asymptomatic swelling remained the same size (Figure 2).

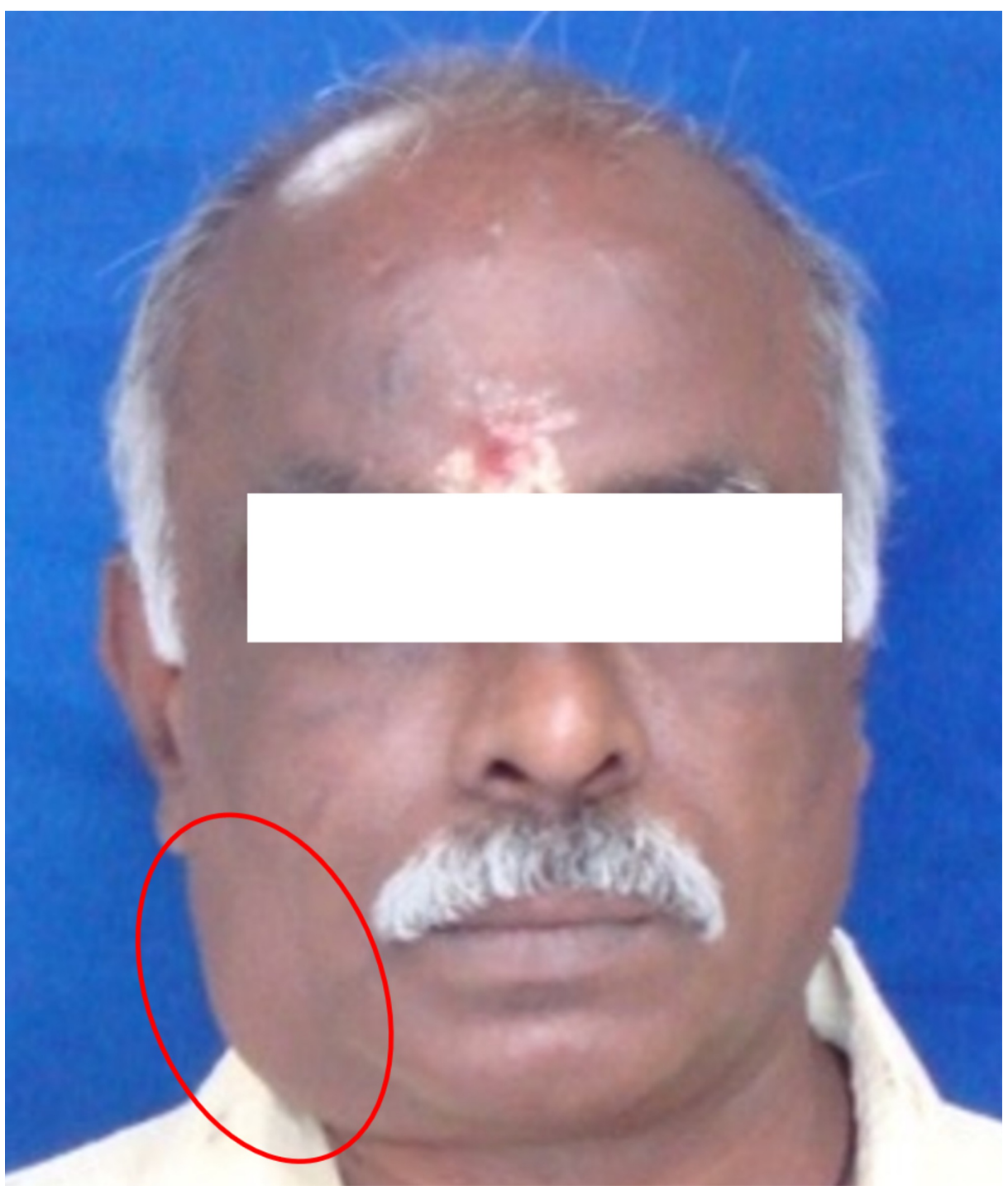

FIGURE 2: Persistent buccal swelling in the right mandibular region after the extraction of tooth 47

There was no cervical lymphadenopathy and, intraorally, the mucosa was normal and moist (Figure 3). The mouth opening was $4.2 \mathrm{~cm}$ inter incisally. The patient could vaguely recollect the presence of a painless small lump for one year, which was brought to his notice by his family members. The patient did not experience pain at any time, nor was there any change in the size of the swelling before and after eating. 


\section{Cureus}

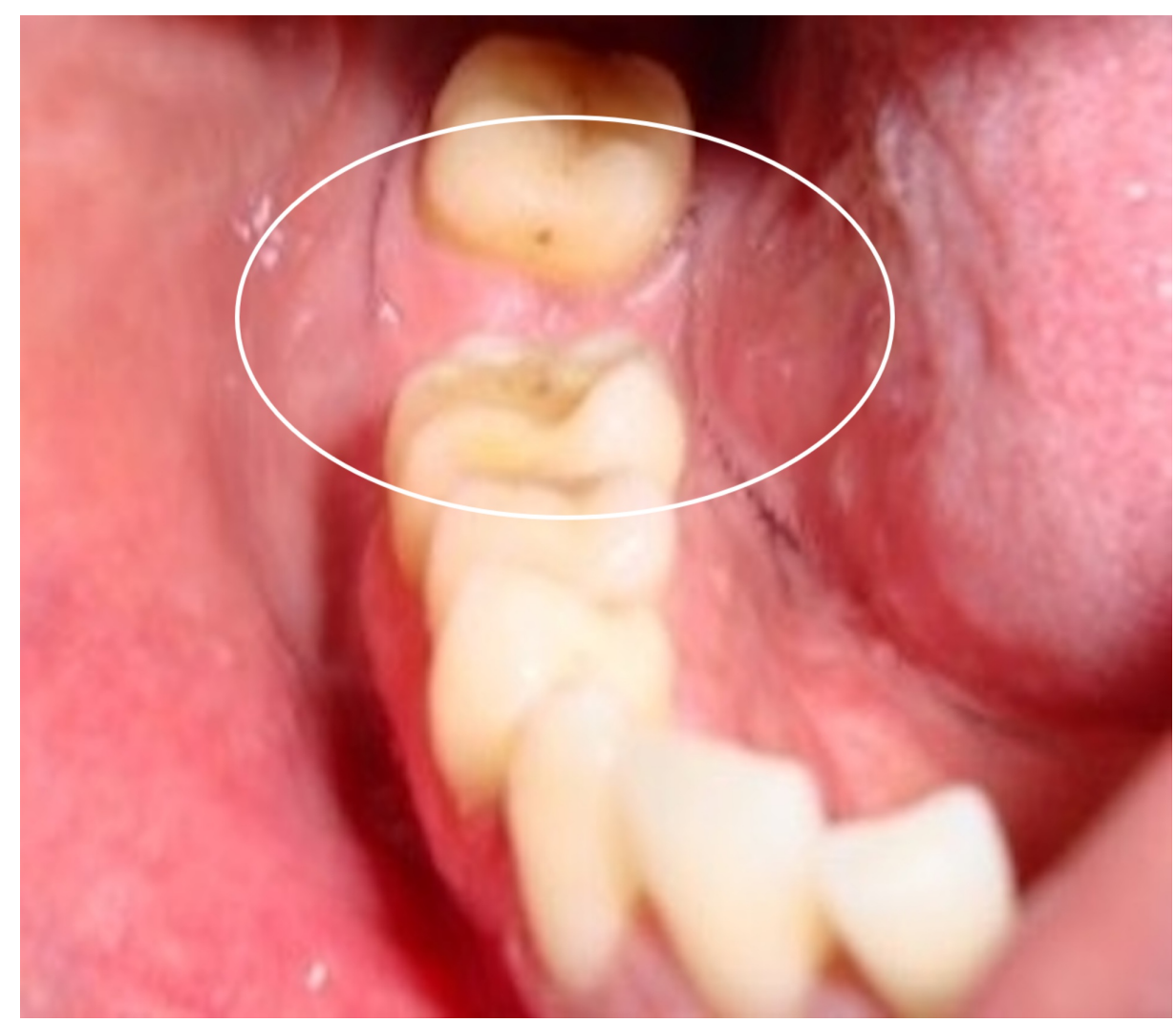

FIGURE 3: Intraoral picture after the extraction of tooth 47 shows normal mucosa

Considering the history of painless swelling lasting one year that was well-defined, soft, nontender, with no intraoral manifestation, a lipoma of the right submandibular region was suspected. Fine needle aspiration cytology was performed under ultrasound guidance. Ultrasonography revealed a well-circumscribed hyperechoic mass measuring $3.2 \mathrm{~cm} \times 2.7 \mathrm{~cm}$ separated from the right submandibular gland (Figure 4). 


\section{Cureus}

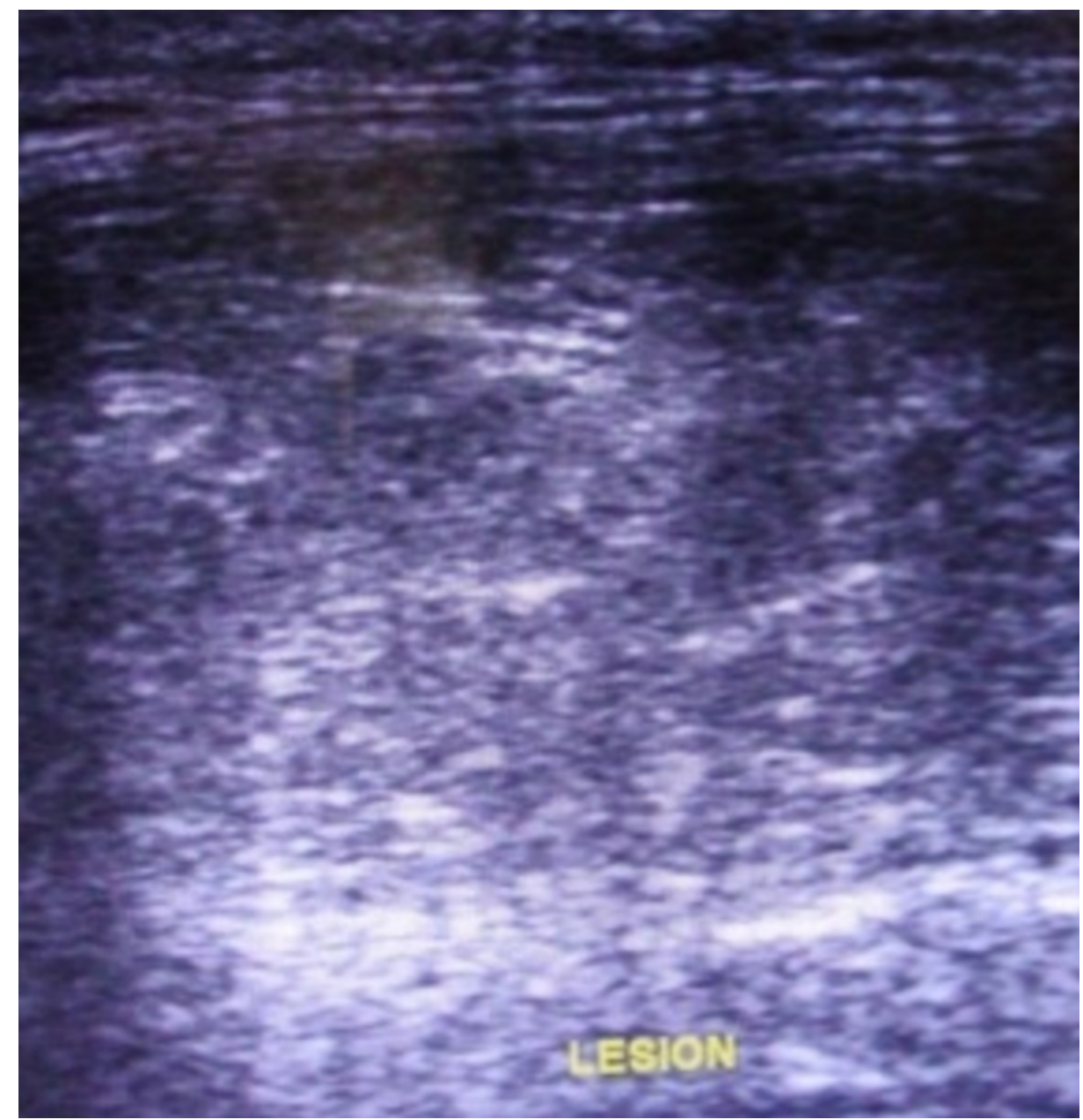

FIGURE 4: Ultrasonography shows a well-circumscribed hyperechoic mass

The smear showed mature fibro-adipose tissue, which would be consistent with a lipoma (Figure 5).

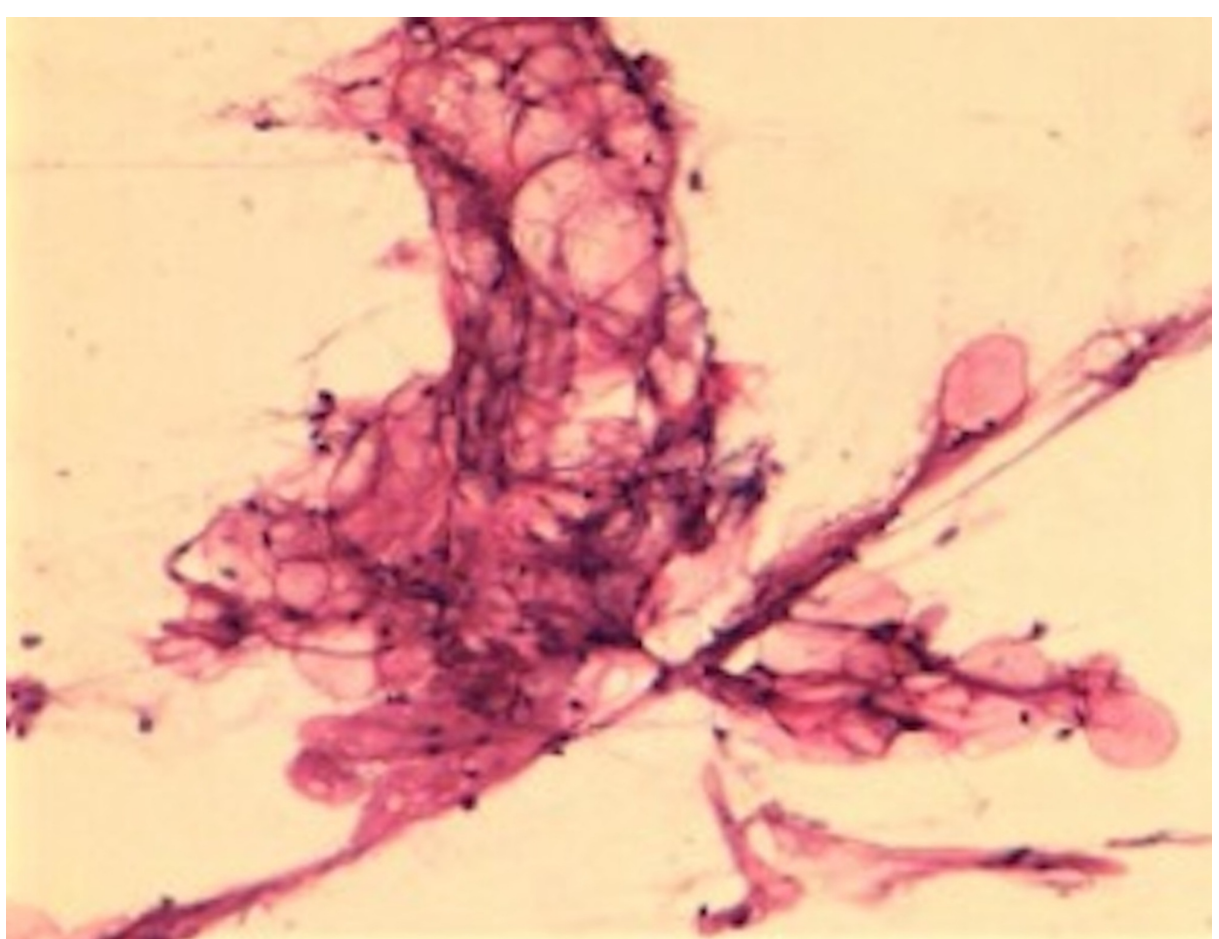


Surgical removal of the lesion was done by the submandibular gland approach under general anesthesia. The excised mass showed mature adipocytes, a few capillaries, and fibro-collagenous tissue. The physical features were again consistent with a lipoma (Figure 6).

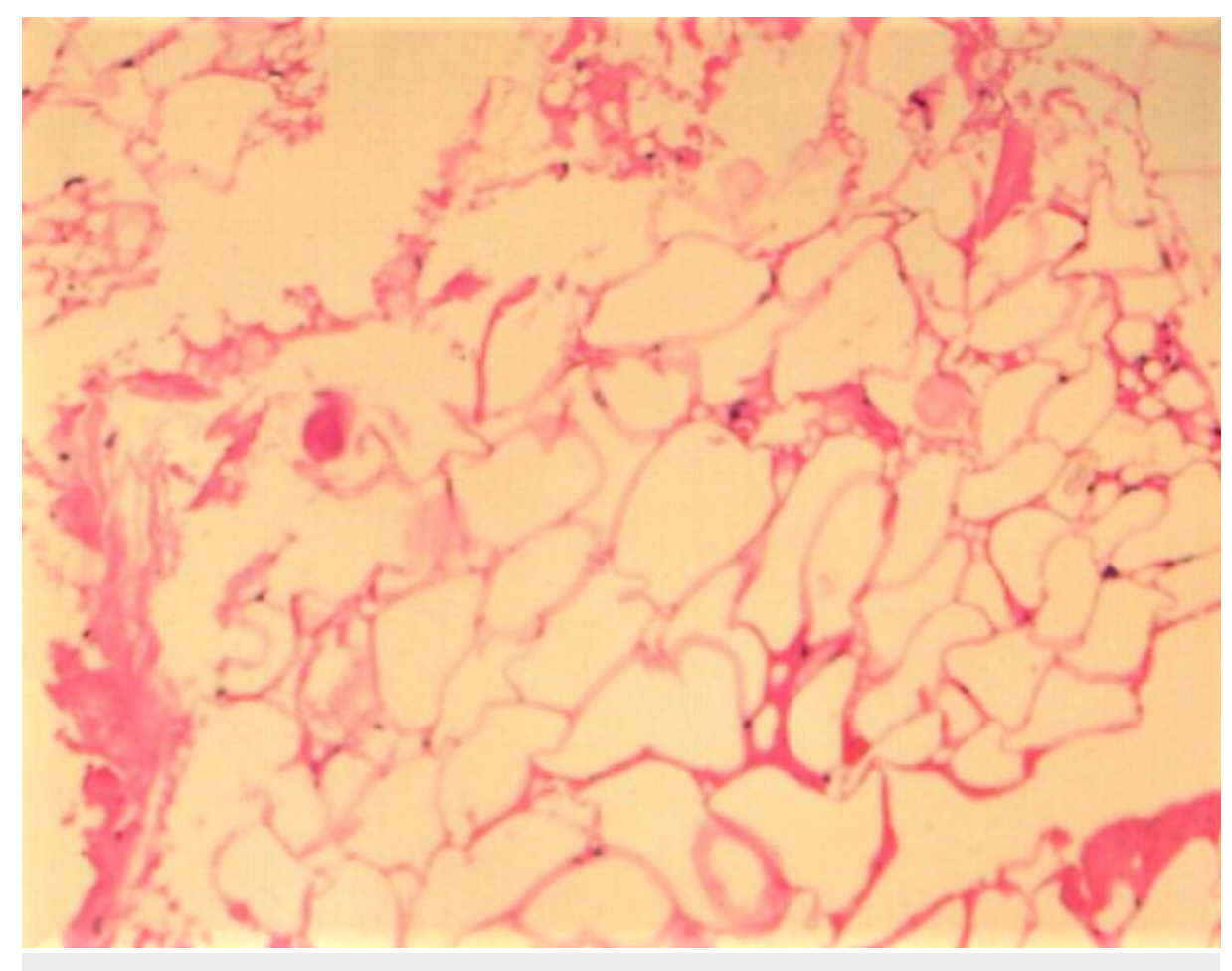

FIGURE 6: Photomicrograph showing mature adipocytes arranged in a lobular pattern with a few capillaries and fibro-collagenous tissue

\section{Discussion}

A complete and accurate history is the basis for an effective care plan. Despite today's medical advancements, a patient's history remains the mainstay for diagnosis. This case presented a rare situation where two distinct, unrelated pathologies (a dental abscess and a lipoma) coexisted, invariably making the clinical course complex. While the buccal aspect of the mandibular body remains an infrequent site for lipomas, its possible presence was masked by the unambiguous signs of odontogenic infection and an incomplete patient history, which naturally led to considerable uncertainty about the source of persistent swelling.

Lipomas are benign tumors of soft tissue origin occurring from mature adipose tissue [1]. It is the most common mesenchymal neoplasm and constitutes $5 \%$ of all benign tumors of the body [6]. The shoulder, back, arm, anterior chest wall, and axilla are the most common sites [2]. Presentation in the head and neck region is relatively rare and constitutes approximately $15 \%$ to $20 \%$ cases. The posterior neck and parotid region are more frequently involved sites [3]. The peak incidence is between the fifth and sixth decade of life [4]. Clinically, lipomas present as soft, painless, slow-growing, well-delineated mobile masses [5].

According to World Health Organization, benign adipocytic tumors are classified into "Lipoma, Lipomatosis, Lipomatosis of nerve, Lipoblastoma/lipoblastomatosis, Angiolipoma, Myolipoma of soft tissue, Chondroid lipoma, Extra-renal angiomyolipoma, Extra-adrenal myelolipoma, Spindle cell/pleomorphic lipoma, and Hibernoma" [7]. The cause of a lipoma remains uncertain. Various pathogenic mechanisms like origin from lipoblastic embryonic cell nest, metaplasia of muscle cells, fatty degeneration, trauma, and infection have been proposed as plausible causative factors [8-10].

Given that a lipoma is a soft tissue neoplasm, ultrasonography (USG) and magnetic resonance imaging (MRI) serve as valuable diagnostic tools. Although lipomas show variable echogenicity, they are usually hyperechoic, containing linear echogenic lines under USG [11]. In T1-weighted MRI images, a lipoma appears as a high-intense mass and with moderate intensity in T2-weighted images [1]. 
Histologically, a lipoma is composed of mature adipocytes arranged in a lobular pattern usually surrounded by a thin fibrous capsule. Although they resemble normal fat cells, they are distinguished from normal adipocytes by the fact that they are not utilized for metabolism. Surgical excision remains the mainstay of treatment, and the recurrence rate is very low $[2,12]$.

\section{Conclusions}

Our patient presented with dental pain and an abscess in the right lower jaw region, a site with a preexisting lipoma. The presence of the lipoma was concealed by the definite signs of a dental abscess. Though the features of lipomas are usually straightforward, systematic clinical examination and diagnostic workup are essential for successful management. We were fortuitous to handle both the abscess and the lipoma successfully, without causing discomfort to the patient. However, we may not always be so fortunate. Therefore, accurate and detailed information regarding a patient's history is indispensable for optimal patient care.

\section{Additional Information \\ Disclosures}

Human subjects: Consent was obtained by all participants in this study. Conflicts of interest: In compliance with the ICMJE uniform disclosure form, all authors declare the following: Payment/services info: All authors have declared that no financial support was received from any organization for the submitted work. Financial relationships: All authors have declared that they have no financial relationships at present or within the previous three years with any organizations that might have an interest in the submitted work. Other relationships: All authors have declared that there are no other relationships or activities that could appear to have influenced the submitted work.

\section{References}

1. Tsuji T, Satoh K, Nakano H, Kida K, Kogo M: Clinical characteristics of lipoma in the submandibular region: report of a relatively uncommon case and review of the literature in Japan. J Oral Maxillofac Surg Med Pathol. 2015, 27:344-347. 10.1016/j.ajoms.2014.03.005

2. Medina CR, Schneider S, Mitra A, Spears J, Mitra A: Giant submental lipoma: case report and review of the literature. Can J Plast Surg. 2007, 15:219-222.

3. Furlong MA, Fanburg-Smith JC, Childers EL: Lipoma of the oral and maxillofacial region: site and subclassification of 125 cases. Oral Surg Oral Med Oral Pathol Oral Radiol Endod. 2004, 98:441-450. 10.1016/j.tripleo.2004.02.071

4. Calhoun KH, Bradfield JJ, Thompson C: Liposuction-assisted excision of cervicofacial lipomas. Otolaryngol Head Neck Surg. 1995, 113:401-403.

5. Chidzonga MM, Mahomva L, Marimo C: Gigantic tongue lipoma: a case report. Med Oral Patol Oral Cir Bucal. 2006, 11:437-439.

6. Enzinger FM, Weiss SW: Benign lipomatous tumors. Soft Tissue Tumors. Mosby, St Louis; 1995. 3:301-345. 10.1002/bjs.1800821050

7. Fletcher CDM, Unni KK, Mertens F: Adipocytic tumors. Pathology and Genetics of Tumours of Soft Tissue and Bone. World Health Organization, IARC Press, Lyon, France; 2002. 5:9-46.

8. Kumaraswamy S, Madan N, Keerthi R, Shakti S: Lipomas of oral cavity: case reports with review of literature. J Maxillofac Oral Surg. 2009, 8:394-397. 10.1007/s12663-009-0096-6

9. Rehani S, Bishen KA: Intraoral fibrolipoma - a case report with review of literature . Indian J Dent Sci. 2010, 2:215-216.

10. Pereira T, Shetty S, Sapdhare S, Tamgadge A: Oral fibrolipoma: a rare histological variant . Indian J Dent Res. 2014, 25:672-674. 10.4103/0970-9290.147123

11. Ahuja AT, King AD, Kew J, King W, Metreweli C: Head and neck lipomas: sonographic appearance. AJNR Am J Neuroradiol. 1998, 19:505-508.

12. Fregnani ER, Pires FR, Falzoni R, Lopes MA, Vargas PA: Lipomas of the oral cavity: clinical findings, histological classification and proliferative activity of 46 cases. Int J Oral Maxillofac Surg. 2003, 32:49-53. 10.1054/ijom.2002.0317 